\title{
Strategi Bank BRI Syariah Dalam Menangani Kredit Bermasalah Di BRI Syaraiah KC. Medan
}

\author{
Arnida Wahyuni Lubis ${ }^{1 *}$, M. Sholeh Shahfithrah ${ }^{2}$ \\ Universitas Islam Negeri Sumatera Utara \\ Email: arnidawahyuni@yahoo.com
}

\begin{tabular}{|c|c|}
\hline Abstrak & \\
\hline $\begin{array}{l}\text { Bank syariah adalah salah satu bentuk dari perbankan } \\
\text { nasional yang mendasarkan operasionalnya pada syariat } \\
\text { (hukum) Islam. Strategi adalah rencana yang di satukan, } \\
\text { menyeluruh dan terpadu yang mengaitkan keunggulan strategi } \\
\text { perusahaan dengan tantangan lingkungan dan di rancang } \\
\text { untuk memastikan bahwa tujuan utama perusahaan dapat di } \\
\text { capai melalui pelaksanaan yang tepat oleh perusahaan. Kredit } \\
\text { adalah penyediaan uang atau tagihan yang dapat } \\
\text { dipersamakan dengan itu, berdasarkan persetujuan atau } \\
\text { kesepakatan pinjam meminjam antara bank dengan pihak lain } \\
\text { yang mewajibkan pihak peminjam untuk melunasi utangnya } \\
\text { setelah jangka waktu tertentu dengan pemberian bunga. } \\
\text { Fenomena di tahun 2015, menunjukkan tingkat Non } \\
\text { Performing Loan(NPL) sebesar 2,06\% dengan Rp. } \\
\text { 14.045.500,00. Yang artinya NPL masih berada ditingkatan } \\
\text { yang baik. Di tahun 2016, NPL sebesar 2,65\% dengan Rp. } \\
\text { 15.927.500,00 meningkat dari tahun 2015. Hal ini disebabkan } \\
\text { kredit macet yang semakin banyak. Tahun 2017, } \\
\text { menunjukaan keadaan yang sebaliknya, Non Performing } \\
\text { Loan (NPL) menurun sebesar 2,65\% (tahun 2016) menjadi } \\
\text { 1,12\% (tahun 2017) Rp. 9.768.500,00. Artinya jumlah kredit } \\
\text { penunggak menurun. Sedangkan dari Loan to Deposit Ratio } \\
\text { (LDR) di tahun 2015 sebesar 48,97\% Rp 1.392.475.000,00 } \\
\text { belum terlalu baik. Di tahun 2016, angka Loan to } \\
\text { Deposit Ratio (LDR) mengalami peningkatan dari 48,97\% } \\
\text { (tahun 2015) menjadi 55,72\% Rp. 1.077.948.000,00, hal ini } \\
\text { disebabkan LDR Baik. Tahun 2017, Loan to Deposit } \\
\text { Ratio(LDR) bertambah sehat dari tahun sebelumnya } \\
\text { ditunjukan dari presentase kenaikan menjadi 72,80\% Rp. } \\
\text { 1.195.248.500,00 dari tahun sebelumnya 55,72\% (tahun } \\
\text { 2016) LDR sudah mengalami peningkatan. NPL atau } \\
\text { pinjaman di tahun } 2016 \text { mengalami kredit macet, sedangkan } \\
\text { LDR atau Deposit ditahun 2015 belum mencapai 50\%. } \\
\text { Penyebabnya kondisi finansial BRI Syariah yang memburuk. } \\
\text { Akibat dari adanya kredit bermasalah yang di alami bank }\end{array}$ & $\begin{array}{c}\text { Received: } \\
10 \text { Februari } 2018 \\
\text { Revised: } \\
13 \text { Maret } 2018 \\
\text { Accepted: } \\
22 \text { Mei 2018 }\end{array}$ \\
\hline
\end{tabular}

Copyright @ 2018. Intiqad: Jurnal Agama dan Pendidikan Islam. This is an open acces article under the CC-BY-SA lisence (https://creativecommons.org/licenses/by-sa/4.0/). 
adalah terjadinya ketidak lancaran perputaran kas di dalam bank yang bersangkutan. Apabila terus berlanjut maka bank tidak akan lagi bisa untuk memberikan kredit kepada nasabah lain dalam jumlah yang besar dikarenakan pihak bank sendiri mengalami kesulitan dalam perputaran arus kas yang di sebabkan oleh kredit bermasalah tadi. Keadaan seperti ini membuat bank tidak lagi mampu membayar utang jangka pendeknya sehingga bank tidak lagi dapat memenuhi likuiditasnya atau dalam keadaan tidak likuid. Selain bank menjadi tidak likuid, terjadinya kredit bermasalah akan mengurangi laba dari bank yang bersangkutan. Strategi penyelesaian pembiayaan kredit di Bank BRI Syariah Kc. Medan menurut yang saya wawancarai saudara Bapak Dicky Himawan adalah strategi kombinasi. Artinya dengan membuat penjadwalan kredit kembali dengan memperpanjang jangka waktu kredit misalkan, menyelamatkan kredit dengan mengubah seluruh atau sebagian perjanjian Misalnya, kapitalisasi suku bunga, dengan menambah jumlah kredit dan menyetor uang tunai.

Keyword: Bank Syariah, Strategi, Kredit

\section{A. Pendahuluan}

BRI Syariah hadir sebagai sebuah bank ritel modern terkemuka dengan layanan finansial berdasarkan kebutuhan nasabah dengan jangkauan termudah untuk kehidupan yang lebih bermakna. Strategi adalah rencana yang di satukan, menyeluruh dan terpadu yang mengaitkan keunggulan strategi perusahaan dengan tantangan lingkungan dan di rancang untuk memastikan bahwa tujuan utama perusahaan dapat di capai melalui

pelaksanaan yang tepat oleh
perusahaan. ${ }^{1}$

Kredit adalah penyediaan uang atau tagihan yang dapat dipersamakan dengan itu, berdasarkan persetujuan atau kesepakatan pinjam meminjam antara bank dengan pihak lain yang mewajibkan pihak peminjam untuk melunasi utangnya setelah jangka waktu tertentu dengan pemberian bunga. ${ }^{2}$

\footnotetext{
${ }^{1}$ Lawrence R. jauch dan William F. Glueck, Manajemen Strategi dan Kebijakan Perusahaan, (Jakarta: Erlangga, 1998), h. 12

2 Djoni S. Gazali, Pengertian dan Dasar Hukum Perbankan, (Jakarta: Sinar Grafika, 2010), h. 4
}

Copyright @ 2018. Intiqad: Jurnal Agama dan Pendidikan Islam. This is an open acces article under the CC-BY-SA lisence (https://creativecommons.org/licenses/by-sa/4.0/). 
Fenomena yang saya teliti adalah Di tahun 2015, menunjukkan tingkat Non Performing Loan (NPL) sebesar 2,06\% dengan Rp. 14.045.500,00. Yang artinya NPL masih berada ditingkatan yang baik. Di tahun 2016, NPL sebesar 2,65\% dengan Rp. 15.927.500,00 meningkat dari tahun 2015. Hal ini disebabkan kredit macet yang semakin banyak. Tahun 2017, menunjukaan keadaan yang sebaliknya, Non Performing Loan (NPL) menurun sebesar 2,65\% (tahun 2016) menjadi 1,12\% (tahun 2017) Rp. 9.768.500,00. Artinya jumlah kredit penunggak menurun. Sedangkan dari Loan to Deposit Ratio (LDR) di tahun 2015 sebesar 48,97\% Rp 1.392.475.000,00 belum terlalu baik. Di tahun 2016, angka Loan to Deposit Ratio (LDR) mengalami peningkatan dari 48,97\% (tahun 2015) menjadi 55,72\% Rp.1.077.948.000,00, hal ini disebabkan LDR Baik. Tahun 2017, Loan to Deposit Ratio(LDR) bertambah sehat dari tahunsebelumnya ditunjukan dari presentase kenaikan menjadi $72,80 \%$ Rp. 1.195.248.500,00 dari tahun sebelumnya 55,72\% (tahun 2016) LDR sudah mengalami peningkatan. NPL atau pinjaman di tahun 2016 mengalami kredit macet, sedangkan LDR atau Deposit ditahun 2015 belum mencapai $50 \%$. Penyebabnya kondisi finansial BRI Syariah yang memburuk. Akibat dari adanya kredit bermasalah yang di alami bank adalah terjadinya ketidak lancaran perputaran kas di dalam bank yang bersangkutan. Apabila terus berlanjut maka bank tidak akan lagi bisa untuk memberikan kredit kepada nasabah lain dalam jumlah yang besar dikarenakan pihak bank sendiri mengalami kesulitan dalam perputaran arus kas yang di sebabkan oleh kredit bermasalah tadi. Keadaan seperti ini membuat bank tidak lagi mampu membayar utang jangka pendeknya sehingga bank tidak lagi dapat memenuhi likuiditasnya atau dalam keadaan tidak likuid. Selain bank menjadi tidak likuid, terjadinya kredit bermasalah akan mengurangi laba dari bank yang bersangkutan.

Lebih jelasnya berikut akan ditampilkan pada table data tahun 2015,2016,2017. 
INTIQAD: JURNAL AGAMA DAN PENDIDIKAN ISLAM

ISSN 1979-9950 (print) || ISSN 2598-0033 (online), http://jurnal.umsu.ac.id/index.php/intiqad DOI: https://doi.org/10.30596/intiqad.v10i1.1920

Published June 2018

\begin{tabular}{|c|c|c|c|}
\hline Keterangan & $\mathbf{2 0 1 5}$ & $\mathbf{2 0 1 6}$ & $\mathbf{2 0 1 7}$ \\
\hline NPL & $2,06 \%$ & $2,65 \%$ & $1,12 \%$ \\
& Rp. $14.045 .500,00$ & Rp. $15.927 .500,00$ & Rp. $9.768 .500,00$ \\
\hline LDR & $48,97 \%$ & $55,72 \%$ & $72,80 \%$ \\
& Rp. $1.392 .475 .000,00$ & Rp. $1.077 .948 .000,00$ & Rp. $1.195 .248 .500,00$ \\
\hline
\end{tabular}

Sumber: Bank BRI Syariah

Strategi penyelesaian pembiayaan kredit di Bank BRI Syariah Kc. Medan menurut yang saya wawancarai saudara Bapak Dicky Himawan adalah strategi kombinasi. Artinya dengan membuat penjadwalan kredit kembali dengan memperpanjang jangka waktu kredit misalkan, menyelamatkan kredit dengan mengubah seluruh atau sebagian perjanjian Misalnya, kapitalisasi suku bunga, dengan menambah jumlah kredit dan menyetor uang tunai.

\section{B. Kajian Teoritis}

\section{Bank Syariah}

\section{1) Pengertian Bank Syariah}

Menurut ketentuan yang tercantum di dalam Peraturan Bank Indonesia nomor2/8/PBI/2000, pasal I, Bank Syariah adalah "bank umum sebagaimana yang dimaksud dalam undang-undang nomor 7 tahun 1992 tentang Perbankan dan telah diubah dengan undang-undang nomor 10 tahun 1998 yang melakukan kegiatan usaha berdasarkan prinsip syari'ah, termasuk unit usaha syariah dan kantor cabang bank asing yang melakukan kegiatan usaha berdasarkan prinsip syari'ah". Adapun yang dimaksud dengan unit usaha syariah adalah unit kerja di kantor pusat bank konvensional yang berfungsi sebagai kantor induk dari kantor cabang syariah. Terdapat perbedaan mendasar antara bank konvensional dan bank syariah. Pertama, dari segi akad dan aspek legalitas. Akad yang praktikkan dalam bank syariah memiliki konsekwensi duniawi dan ukhrawi, dunia dan akhirat, karena akad yang dilakukan berdasarkan hukum atau syari'at Islam. Jika terjadi perselisihan antara nasabah dan bank, maka bank syariah dapat merujuk kepada Badan Arbitrase Muamalat Indonesia (BAMUI) yang penyelesaiannya dilakukan berdasarkan hukum Islam. 
Kedua, dari sisi struktur organisasi, Bank Syariah dapat memiliki struktur yang sama dengan bank konvensional, namun unsur yang membedakannya adalah bahwa bank syariah harus memilki Dewan Pengawas Syariah yang bertugas mengawasi operasional dan produk-produk bank agar sesuai dengan ketentuan-ketentuan syari'ah Islam. Eksistensi Dewan Syariah di dalm struktur organisasi bank syariah adalah wajib, bahkan bagi setiap bank yang bersekala kecil sekalipun, seperti Bank Perkreditan Rakyat Syariah (BPRS) atau Baitul Mal Wat Tamwil (BMT) harus mempunyai Dewan Pengawas Syariah. Ketiga, berkenaan dengan bisnis dan usaha yang dibiyai, haruslah bisnis dan usaha yang diperkenankan atau dihalalkan oleh syari'at Islam. Kehalalan bisnis dan usaha merupakan syarat mutlak agar suatu bidang usaha itu halal untuk dibiayai oleh perbankan syariah. Karena itulah, secara langsung atau tidak langsung perbankan Islam tidaklah semata-mata merupakan institusi ekonomi, tetapi juga sebagai institusi yang ikut bertanggung jawab menjaga moral dan akhlak masyarakat. Keempat, berkaitan dengan lingkungan kerja dan budaya perusahaan perbankan (Corporate culture). Dalam hal etika, sifat shiddiq (jujur), amanah (dapat dipercaya), fathanah (cerdas, professional) dan tabligh (komunikatif, ramah, keterbukaan) harus melandasi setiap tindakan para pelaku perbankan syariah. Dalam hal reward and punishment yang berlaku dalam perbankan syariah dipraktikkan dengan prinsip berkeadilan dan sesuai dengan syari'ah.

\section{2) Landasan Hukum Perbankan}

\section{Islam}

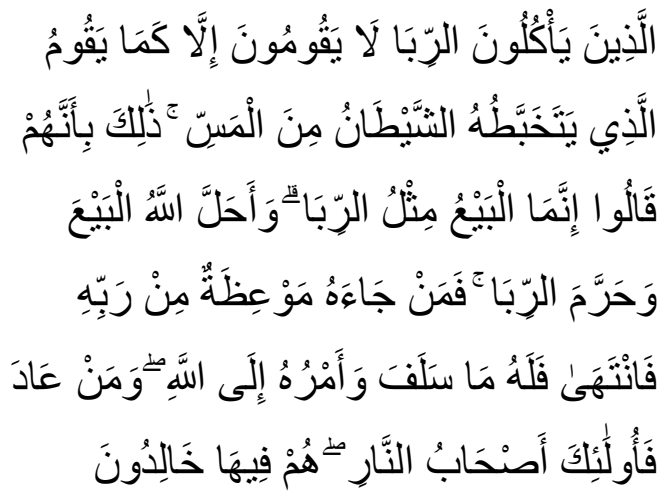

Artinya: Orang-orang yang makan (mengambil) riba tidak dapat berdiri melainkan seperti berdirinya orang yang kemasukan syaitan lantaran (tekanan) penyakit gila. Keadaan mereka yang demikian itu, adalah disebabkan mereka berkata (berpendapat), sesungguhnya jual beli itu sama dengan riba, padahal Allah telah menghalalkan jual beli dan 
mengharamkan riba. Orang-orang yang telah sampai kepadanya larangan dari Tuhannya, lalu terus berhenti (dari mengambil riba), maka baginya apa yang telah diambilnya dahulu (sebelum datang larangan); dan urusannya (terserah) kepada Allah. Orang yang kembali (mengambil riba), maka orang itu adalah penghuni-penghuni neraka; mereka kekal di dalamnya. (Q.S Al Baqarah: 275) ${ }^{3}$

\section{3) Strategi}

Strategi adalah rencana yang di satukan, menyeluruh dan terpadu yang mengaitkan keunggulan strategi perusahaan dengan tantangan lingkungan dandi rancang untuk memastikan bahwa tujuan utamaperusahaan dapat di capai melalui pelaksanaan yang tepat oleh perusahaan. ${ }^{4}$

\section{Kredit Bermasalah.}

1) Pengertian Kredit Bermasalah

Kredit bermasalah merupakan kredit yang telah disalurkan oleh bank, dan nasabah tidak dapat melakukan pembayaran atau melakukan

\footnotetext{
${ }^{3}$ Departemen Agama Republik Indonesia, Al-Quran dan Terjemah (Jakarta: Lajnah Pentashih Mushaf al-Quraan), hal.47.

${ }^{4}$ Lawrence R. jauch dan William F. Glueck, Manajemen Strategi dan Kebijakan Perusahaan, (Jakarta: Erlangga, 1998), h. 12
}

angsuran sesuai dengan perjanjian yang telah di tanda tangani oleh bank dan nasabah. Beberapa pengertian mengenai kategori kolektibilitas kredit berdasarkan ketentuan yang dibuat Bank Indonesia, sebagai berikut.

a. Kredit Lancar, kredit yang tidak mengalami penundaan pengembalian pokok pinjaman dan pembayaran bunga.

b. Kredit dengan perhatian khusus, merupakan kredit yang masih digolongkan lancar, akan tetapi mulai terdapat tunggakan. Ditinjau dari segi kemampuan membayar, yang tergolong kredit dalam perhatian khusus apabila terdapat tunggakan angsuran pokok dan/atau bunga sampai dengan 90 hari.

c. Kredit Kurang Lancar, kredit yang pengembalian pokok pinjaman dan pembayaran bunganya telah melampaui 90 hari sampai dengan kurang dari 180 hari dari waktu yang diperjanjikan.

d. Kredit Diragukan, kredit yang pengembalian pokok pinjaman dan pembayaran bunganya telah mengalami penundaan selama 180 
hari hingga 270 hari atau dua kali dari jadwal yang diperjanjikan.

e. Kredit Macet, kredit yang pokok pinjaman dan pembayaran bunganya telah mengalami penundaan melampaui 270 hari atau lebih sejak jatuh tempo.

\section{2) Faktor Penyebab Kredit}

\section{Bermasalah}

Faktor penyebab kredit bermasalah menurut W. Rees Edward, K. Gill Edward terdapat 2 faktor yaitu faktor internal dan faktor eksternal.

a. Faktor internal yang menjadi penyebab timbulnya kredit bermasalah yaitu:

a) Kebijakan perkreditan yang ekspansif.

b) Penyimpanan dalam pelaksanaan prosedur perkreditan.

c) Itikad kurang baik dari pemilik, pengurus atau pegawai Bank.

d) Lemahnya sistem administrasi dan pengawasan kredit serta lemahnya sistem informasi kredit bermasalah.

b. Faktor eksternal penyebab timbulnya kredit bermasalah adalah:

a) Kegagalan usaha debitur. b) Musibah terhadap debitur atau terhadap kegiatan usaha debitur.

c) Pemanfaatan iklim persaingan perbankan yang tidak sehat oleh debitur.

d) Menurunnya kegiatan ekonomi dan tingginya suku bunga kredit.

\section{3) Strategi Penyelesaian Kredit Bermasalah}

Kredit bermasalah atau macet memaksa bank atau lembaga keuangan lainnya untuk melakukan strategi penyelesaian kredit bermasalah sehingga tidak menimbulkan kerugian. Penyelesaian kredit bermasalah dapat dilakukan dengan memberikan keringanan berupa jangka jangka waktu atau jumlah angsuran terutama bagi kredit yang terkena musibah atau dengan melakukan penyitaan bagi kredit yang sengaja lalai untuk membayar.

Strategi penyelesaian kredit bermasalah dilakukan dengan beberapa cara yaitu:

\section{a. Rescheduling}

Rescheduling merupakan upaya yang dilakukan bank untuk menangani kredit bermasalah dengan membuat penjadwalan kembali. 


\begin{abstract}
Penjadwalan kembali dapat dilakukan kepada debitur yang mempunyai itikad baik akan tetapi tidak memiliki kemampuan untuk membayar angsuran pokok maupun angsuran bunga dengan jadwal yang telah diperjanjikan. Penjadwalan kembali dilakukan oleh bank dengan harapan debitur dapat membayar kembali kewajibannya. Beberapa alternatif rescheduling yang dapat diberikan bank antara lain:
\end{abstract}

a) Memperpanjang Jangka Waktu Kredit

Memperpanjang jangka waktu kredit dilakukan dengan cara debitur diberikan keinginan dalam masalah jangka waktu kredit misalnya perpanjangan jangka waktu kredit dari 6 bulan menjadi satu tahun sehingga debitur mempunyai waktu yang lebih lama untuk mengembalikannya.

b) Memperpanjang Jangka Waktu Angsuran

$\begin{array}{lr}\text { Memperpanjang } & \text { angsuran } \\ \text { dilakukan dengan } & \text { cara jangka } \\ \text { waktu angsuran } & \text { kreditnya } \\ \text { diperpanjang } & \text { pembayarannya } \\ \text { misalnya dari } & 36 \text { kali menjadi } 48\end{array}$ kali dan jumlah angsurannya menjadi mengecil seiring dengan penambahan jumlah angsuran.

\section{b. Reconditioning}

Reconditioning merupakan upaya bank dalam menyelamatkan kredit dengan mengubah seluruh atau sebagian perjanjian yang telah dilakukan oleh bank dengan nasabah. Perubahan kondisi dan persyaratan tersebut harus disesuaikan dengan permasalahan yang dihadapi oleh debitur dalam menjalankan usahanya. Dengan perubahan persyaratan tersebut, maka diharapkan bahwa debitur dapat menyelesaikan kewajibannya sampai dengan lunas. ${ }^{5}$

Reconditioning dilakukan dengan cara mengubah berbagai cara persyaratan yang ada seperti:

a) Kapitalisasi bunga, yaitu bunga dijadikan hutang pokok.

b) Penundaan pembayaran bunga sampai waktu tertentu.

Penundaan pembayaran bunga sampai waktu tertentu adalah

${ }^{5}$ Lukman Dendawijaya, Manajemen Perbankan (Jakarta : Ghalia Indonesia 2005), hlm 83 
penundaan bunga sedangkan pokok pinjamannya tetap harus dibayar seperti biasa.

c) Penururunan suku bunga.

$\begin{array}{lrr}\text { Penurunan } & \text { suku } & \text { bunga } \\ \text { dimaksudkan } & \text { agar } & \text { lebih } \\ \text { meringankan } & \text { beban } & \text { debitur. }\end{array}$
Sebagai contoh jika bunga per tahun sebelumnya dibebankan $20 \%$ diturunkan menjadi $18 \%$, hal ini tergantung dari pertimbangan yang bersangkutan. Penurunan suku bunga akan mempengaruhi jumlah angsuran yang semakin kecil, sehingga diharapkan dapat membantu meringankan debitur.

d) Pembebasan bunga.

Pembebasan bunga diberikan kepada debitur dengan pertimbangan debitur akan mampu lagi membayar kredit tersebut dengan catatan debitur tetap mempunyai kewajiban untuk membayar pokok pinjamannya sampai lunas.

\section{c. Restructuring}

Restructuring merupakan upaya yang dilakukan oleh bank dalam menyelamatkan kredit bermasalah dengan cara mengubah struktur pembiayaan yang mendasari pemberian kredit.

Restructuring dilakukan dengan cara sebagai berikut:

a) Dengan menamabah jumlah kredit.

b) Dengan menambah equity:

$\checkmark$ Dengan menyetor uang tunai

$\checkmark$ Tambahan modal dari pemilik

c) Kombinasi.

Kombinasi merupakan gabungan ketiga jenis yang di atas.

d) Penyitaan Jaminan.

Penyitaan jaminan merupakan jalan terakhir apabila debitur sudah benar-benar tidak mampu lagi untuk membayar semua hutanghutangnya.

\section{Metode Penelitian}

Metode penelitian adalah sekumpulan teknik atau cara yang digunakan dalam penelitian yang meliputi proses perencanaan dan pelaporan hasil penelitian.

\section{Jenis Penelitian}

Penelitian ini adalah penelitian lapangan dengan menggunakan pendekatan kualitatif, yaitu prosedur penelitian yang menghasilkan data deskriptif berupa kata-kata tertulis atau 
lisan dari orang-orang dan perilaku yang dapat diamati. ${ }^{6}$ Jadi penelitian ini adalah penelitian yang menghasilkan prosedur analisis yang tidak menggunakan prosedur analisis statistik atau cara kuantifikasi lainnya. ${ }^{7}$

\section{Sumber Data Penelitian}

Adapun sumber data yang digunakan pada kali ini ada dua macam yaitu:

1) Data Primer

Data primer adalah data yang diperoleh secara langsung dari objek penelitian sebagai sumber informasi yang dicari. ${ }^{8}$ Data primer juga disebut dengan data yang diperoleh peneliti dari sumber asli. ${ }^{9}$ Data primer juga disebut dengan data yang diperoleh peneliti dari Sumber data primer dalam penelitian ini adalah hasil wawancara langsung dengan pihak BRIS cabang Medan yang dilakukan dengan Bapak Arif Miftakhul

${ }^{6}$ Lexy J. Moleong, Metodologi Penelitian Kualitatif, Cet. 21, (Bandung: PT. Remaja Rosdakarya, 2005), h. 4.

${ }^{7}$ Lexy J. Moloeng, Op.Cit, h. 248

${ }^{8}$ Saifudin Azwar, Metodologi Penelitian, (Yogyakarta: Pustaka Pelajar, 1998), h. 91

${ }^{9}$ Muhammad, Metodologi Penelitian Ekonomi Islam: Pendekatan Kualitatif, (Jakarta: PT. Raja Grafindo Persada, 2008), h.103.
Huda selaku Marketing, Bapak Dicky Himawan selaku Account Officer (AO).

2) Data Sekunder

Data Sekunder adalah data yang mendukung data primer dan dapat diperoleh dari luar objek penelitian. ${ }^{10}$ Sumber data sekunder dalam penelitian ini adalah segala data yang tidak berasal dari sumber data primer yang dapat memberikan dan melengkapi serta mendukung informasi terkait dengan objek penelitian baik yang berbentuk buku, karya tulis, dan tulisan maupun artikel yang berhubungan dengan objek penelitian

\section{Hasil Penelitian dan Pembahasan}

\section{Non Perfoming Loan (NPL)}

Non Perfoming Loan (NPL) merupakan analisis untuk kredit bermasalah yang terdiri dari kreditkredit dalam kolektibilitas Kurang Lancar, Kredit yang diragukan, serta Kredit Macet.

Perhitungan Non Perfoming Loan (NPL) yaitu: 
Rasio Non Perfoming Loan $=$ Non

Perfoming Loan x $100 \%$

Jumlah Pinjaman

a. Perhitungan Non Perfoming Loan

(NPL) untuk tahun 2015 adalah:

1) Kredit Kurang Lancar:

$$
\text { Rp 8.296.000,00 }
$$

2) Kredit Diragukan:

$$
\text { Rp 4.137.500,00 }
$$

3) Kredit Macet:

$\underline{\operatorname{Rp} 1.612 .000,00+}$

Jumlah: Rp 14.045.500,00

b. Jumlah Pinjaman tahun $2015 \mathrm{Rp}$

$681.931 .500,00$

Rasio Non Perfoming Loan (NPL)

$=14.045 .500,00 \times 100$

$\% 681.931 .500,00=2,06 \%$

Sedangkan perhitungan Non

Perfoming Loan (NPL) untuk tahun

2016 adalah:

a. Non Perfoming Loan (NPL) tahun

2016

1) Kredit Kurang Lancar

Rp 9.967.500,00

2) Kredit Diragukan

$$
\text { Rp 1.532.000,00 }
$$

3) Kredit Macet

$$
\underline{\operatorname{Rp} 4.428 .000,00+}
$$

Jumlah

$$
\text { Rp 15.927.500,00 }
$$

b. Jumlah Pinjaman tahun $2016 \quad$ Rp $600.659 .500,00$

Rasio Non Perfoming Loan (NPL)= $15.927 .500,00 \times 100 \%$ $600.659 .500,00=2,65 \%$

Dan Non Perfoming Loan untuk tahun 2017 adalah:

a. Non Perfoming Loan (NPL) tahun 2017 adalah:

1) Kredit Kurang Lancar

$$
\text { Rp 3.981.000,00 }
$$

2) Kredit Diragukan

$$
\text { Rp 4.024.000,00 }
$$

3) Kredit Macet

Jumlah

$\underline{\operatorname{Rp} 1.763 .500,00+}$

Rp 9.768.500,00

b. Jumlah Pinjaman tahun 2017

Rp 870.093.500,00

Rasio Non Perfoming Loan (NPL)=

9.768.500,00 x $100 \%$

$870.093 .500,00=1,12 \%$

\section{Loan to Deposit Ratio (LDR)}

Loan to Deposit Ratio (LDR) adalah analisis pengukuran yang menunjukan deposito berjangka, giro, tabungan dan lain-lain yang digunakan dalam

memenuhi permohonan pinjaman nasabahnya. Loan to Deposit Ratio (LDR) digunakan untuk mengukur 
komposisi pinjaman (Kredit) yang

diberikan dibandingkan dengan

jumlah simpanan dana daru

masyarakat.

Rumusnya:

Loan to Deposir Ratio = Jumlah

Pinjaman x 100\% Jumlah Simpanan

a. Perhitungan Loan to Deposit Ratio

tahun 2015:

1) Jumlah Pinjaman

$$
\text { Rp 681.931.500,00 }
$$

2) Jumlah Simpanan

$$
\text { Rp 1.392.475.000,00 }
$$

Loan to Deposit Ratio $(\mathrm{LDR})=$ $681.931 .500,00 \times 100 \%$

$$
\text { 1.392.475.000, } 00=48,97 \%
$$

b. Perhitungan Loan to Deposit Ratio (LDR) tahun 2016:

1) Jumlah Pinjaman

$$
\text { Rp 600.659.500,00 }
$$

2) Jumlah Simpanan

Rp 1.077.948.000,00

Loan to Deposit Ratio $(\mathrm{LDR})=$ $600.659 .500,00 \times 100 \%$

$1.077 .948 .000,00=55,72 \%$

c. Loan to Deposit Ratio (LDR) tahun 2017:

1) Jumlah Pinjaman

$$
\text { Rp 870.093.500,00 }
$$

2) Jumlah Simpanan

Rp 1.195.248.500,00

Loan to Deposit Ratio $(\mathrm{LDR})=$ $870.093 .500,00 \times 100 \%$

$$
1.195 .248 .500,00=72,80 \%
$$

Dari data diatas diketahui hasil perhitungan Ratio Non Perfoming Loan (NPL) dan Loan to Deposit Ratio dari tahun ke tahun mengalami berubahan. Untuk lebih jelasnya berikut akan ditampilkan pada table.

Hasil Perhitungan NPL dan LDR PT BRIS Kc. Medan 2015, 2016, 2017

\begin{tabular}{|c|c|c|c|}
\hline Keterangan & $\mathbf{2 0 1 5}$ & $\mathbf{2 0 1 6}$ & $\mathbf{2 0 1 7}$ \\
\hline NPL & $2,06 \%$ & $2,65 \%$ & $1,12 \%$ \\
& Rp. $14.045 .500,00$ & Rp. $15.927 .500,00$ & Rp. $9.768 .500,00$ \\
\hline LDR & $48,97 \%$ & $55,72 \%$ & $72,80 \%$ \\
& Rp. $1.392 .475 .000,00$ & Rp. $1.077 .948 .000,00$ & Rp. $1.195 .248 .500,00$ \\
\hline
\end{tabular}

Sumber: Bank BRI Syariah

Dari hasil Non Perfoming Loan (NPL) dapat diketahui bahwa Non Perfoming dari tahun ke tahun maka Loan (NPL). 
1) Tahun 2015, menunjukan tingkat Non Perfoming Loan (NPL) sebesar 2,06\%. Yang artinya Non Perfoming Loan masih berada ditingkatan yang baik karena berada dibawah parameter kebijakan Bank Rakyat Indonesia Syariah yaitu di bawah angka $3 \%$ penunggakannya. Dan dalam siatuasi ini ekspansi penyaluran Kredit di Kc Medan masih dapat dilakukan sesuai aturan.

2) Tahun 2016, tahun ini Non Perfoming Loan (NPL) sebesar 2,65\% meningkat dari tahun 2015 . Hal ini disebabkan kredit macet yang semakin banyak dapat kita lihat Non Perfoming Loan (NPL) meningkat $\mathrm{Rp}$ $14.045 .500,00$ (tahun 2015) menjadi $\quad \mathrm{Rp} \quad 15.927 .500,00$ (tahun 2016). Sedangkan jumlah kredit/pinjaman mengalami penurunan dari $\mathrm{Rp}$ 681.931.500,00 (tahun 2015) menjadi Rp 600.659.500,00 (tahun 2016). Penurunan kredit dan tunggakan yang semakin meningkat otomatis membuat kerugian sehingga penurunan profit pun pasti di rasakan oleh pihak bank.

3) Tahun 2017, pada tahun ini menunjukan keadaan yang sebaliknya, ratio Non Perfoming Loan menurun sebesar $2,65 \%$ (tahun 2016) menjadi $1,12 \%$ (tahun 2017). Artinya jumlah kredit penunggak menurun dari total rupiah sebesar $\mathrm{Rp} 15.927 .500,00$ (tahun 2016) dan kini hanya $\begin{array}{lll}\text { sebesar } \quad \mathrm{Rp} & 9.768 .500,00\end{array}$ (tahun 2017)

penurunan penunggakannya/ Non Perfoming Loan (NPL) dan peningkatan jumlah pinjaman sebesar $\quad \mathrm{Rp}$ 600.659.500,00 menjadi Rp 870.093.500,00. Demikian

dapat terlihat dari turunnya jumlah penunggak dan disertai naiknya jumlah pinjaman kredit ini berarti upaya pihak Manajemen PT Bank Rakyat Indonesia Syariah Kc. Medan berhasil dalam penangulangan kredit-kredit bermasalah dan masih dapat mempertahankan predikat 
baik dari parameter kebijakan PT BRIS.

Adapun tingkat kesehatan suatu bank dapat kita tinjau dari segi/pengukuran rasio keuangan yaitu Loan to Deposit Ratio yang akan kita bahas dari tahun 2015 hingga 2017 berikut:

1) Tahun 2015, Loan to Deposit Ratio sebesar 48,97\% yang diperoleh dariperbandingan antara total pinjaman (kredit/loan) sebesar $\mathrm{Rp}$

681.931.500,00 dengan total simpanan sebesar Rp 1.392.475.000,00 hal ini menunjukan total pinjaman/ kredit yang ada belum dikatakan maksimal karena total pinjaman/kredit belum mencapai $50 \%$ dari total simpanan atau dana yang dapat dikelola pihak bank dalam penyaluran kredit saat ini. Keadaan ini membuktikan bahwa Loan to Deposit Ratio (LDR) tahun 2015 belum tertalu baik dan harus lebih maksimal dalam ekspansi penyaluran kreditnya.
2) Tahun 2016, angka Loan to Deposit Ratio (LDR) mengalami peningkatan dari 48,97\% (tahun 2015) menjadi $55,72 \%$ di tahun ini, hal ini disebabkan penurunan jumlah pinjaman (kredit/loan) dari Rp 681.931.500,00 (tahun 2015) menjadi 600.659.500,00 (tahun 2016) dan diimbangi penurunan jumlah simpanan (deposit) yaitu dari $\operatorname{Rp~1.392.475.000,00~(tahun~}$ 2015) menurun menjadi Rp 1.077.948.000,00 (tahun 2016). Penurunan jumlah pinjaman dan simpanan tahun 2016 ini masih menunjukan angka prosentase yang baik untuk kesehatan suatu bank, walau pun pinjaman/kredit menurun dan simpanan menurun dari tahun sebelumnya tetapi Loan to Deposit Ratio (LDR) masih dikatakan baik dan bank masih dikatakan sehat karena prosentase akhir dari perhitungan ratio keuangan Loan to Deposit Ratio (LDR) meningkat 50\% lebih dari total simpanan yang ada pada tahun 2016 yang artinya dari penurunan total simpanan 
tahun 2016pihak manajemen PT

Bank

Rakyat Indonesia

Syariah Kc. Medan berhasil dalam ekpansi penyaluran kredit.

3) Tahun 2017, Loan to Deposit Ratio (LDR) bertambah sehat dari tahun sebelumnya ditunjukan dari prosentase kenaikan menjadi $72,80 \%$ dari tahun sebelumnya $55,72 \%$ (tahun 2016). Hal ini karena peningkatan jumlah pinjaman /loan $\quad \mathrm{Rp}$ 600.659.500,00 (tahun 2016) menjadi $\quad \operatorname{Rp} 870.093 .500,00$ (tahun 2017) berimbang dengan peningkatan jumlah simpanan (deposit) yaitu dari $\mathrm{Rp}$ 1.077.948,00 meningkat menjadi Rp 1.195.248.500,00 berarti nilai likuiditas Bank Rakyat Indonesia Syariah Kc. Medan semakin meningkat dari perioade 2015 hingga periode tahun 2016. Dapat terlihat jelas di tahun 2016 peningkatan jumlah pinjaman yang artinya ekspasi berjalan baik walaupun jumlah simpanan tahun ini meningkatpun manajeman BRIS Kc. Medan tetap dapat melakukan penyaluran kredit hingga lebih baik dari tahun-tahun sebelumnya.

\section{Strategi Penyelesaian}

\section{Pembiayaan kredit}

Strategi penyelesaian pembiayaan kredit di Bank BRI Syariah Kc. Medan adalah strategi kombinasi. Artinya dengan membuat penjadwalan kredit kembali dengan memperpanjang jangka waktu kredit misalkan, menyelamatkan kredit dengan mengubah seluruh atau sebagian perjanjian Misalnya, kapitalisasi suku bunga, dengan menambah jumlah kredit dan menyetor uang tunai.

\section{E. Penutup}

1. Kesimpulan

1) Non Performing Loan (NPL) Di tahun 2015, menunjukkan tingkat Non Performing Loan (NPL) sebesar 2,06\% dengan Rp. 14.045.500,00. Yang artinya NPL masih berada ditingkatan yang baik. Di tahun 2016, NPL sebesar 2,65\% dengan Rp. 15.927.500,00 meningkat dari tahun 2015. Hal ini disebabkan kredit macet yang semakin banyak. Tahun 2017, menunjukaan keadaan yang sebaliknya, Non Performing Loan 
(NPL) menurun sebesar $2,65 \%$ (tahun 2016) menjadi 1,12\% (tahun 2017) Rp. 9.768.500,00. Artinya jumlah kredit penunggak menurun. Sedangkan dari Loan to Deposit Ratio (LDR) di tahun 2015 sebesar $48,97 \%$ Rp 1.392.475.000,00 belum terlalu baik. Di tahun 2016, angka Loan to Deposit Ratio (LDR) mengalami peningkatan dari $48,97 \% \quad$ (tahun 2015) menjadi 55,72\% Rp. 1.077.948.000,00, hal ini disebabkan LDR Baik. Tahun 2017, Loan to Deposit Ratio(LDR) bertambah sehat dari tahun sebelumnya ditunjukan dari presentase kenaikan menjadi 72,80\% Rp. 1.195.248.500,00 dari tahun sebelumnya $55,72 \%$ (tahun 2016) LDR sudah mengalami peningkatan. NPL atau pinjaman di tahun 2016 mengalami kredit macet, sedangkan LDR atau Deposit ditahun 2015 belum mencapai $50 \%$. Penyebabnya kondisi finansial BRI Syariah yang memburuk.

2) Strategi penyelesaian pembiayaan kredit di Bank BRI Syariah Kc.
Medan adalah strategi kombinasi. Artinya dengan membuat penjadwalan kredit kembali dengan memperpanjang jangka waktu kredit misalkan, menyelamatkan kredit dengan mengubah seluruh atau sebagian perjanjian Misalnya, kapitalisasi suku bunga, dengan menambah jumlah kredit dan menyetor uang tunai.

\section{Saran}

1) Permasalahan kredit bermasalah menjadi resiko semua bank yang mempunyai fasilitas penyalur kredit, tetapi kredit bermasalah sebenarnya dapat dipantau oleh bank itu sendiri. Sebaiknya setiap bank lebih menerapkan prinsip kehatihatian dalam menyalurkan kreditnya.

2) Data pengawasan terhadap debitur (nasabah) yang memerlukan perhatian khusus, dan melakukan penagihan secara intensif pada debitur penunggak. Maka disaran kan Bank Rakyat Indonesia Syariah (BRIS) Kc. Medan dapat terus melakukan perbaikanperbaikan dalam penyaluran kredit, 
INTIQAD: JURNAL AGAMA DAN PENDIDIKAN ISLAM

ISSN 1979-9950 (print) || ISSN 2598-0033 (online), http://jurnal.umsu.ac.id/index.php/intiqad DOI: https://doi.org/10.30596/intiqad.v10i1.1920

Published June 2018

selektif dalam proses

penyaluran kredit sehingga

terhindar dari kondisi finansial

yang memburuk akibat kredit

bermasalah yang semakin banyak

dan tentunya terhindar dari resiko

kredit bermasalah yang tak tertagih.

\section{Daftar Pustaka}

Algaound, latifa dan lewis. 2001

Perbankan Syariah Prinsip Praktik

Prospek. Jakarta: Serambi Ilmu

Semesta.

Arifin, zainul. 1999. Memahami Bank

Syariah. Jakarta: Alvabet.

Buchori, Nur S. 2012. KoperasiSyariah.

Banten: PustakaAufa Media

David, Fred R. 2004.Manajemen

Strategis Konsep-Konsep Edisi

Kesembilan. Jakarta: Indeks

Kelompok Gramedia.

Djoko, muljono. 2012. Buku Pintar

Strategi Bisnis Koperasi Simpan

Pinjam. Yogyakarta: ANDI.

Hasibuan, Malayu.2008. Dasar-Dasar

Perbankan. Jakarta: BumiAksara.

Kasmir. 2002. Dasar-Dasar Perbankan.

Jakarta: Raja Grafindo.
Sugiyono. 2011. Metode Penelitian

Kuantitatif, Kualitatif, dan $R \& D$.

Bandung: AFABET

Djoni S. Gazali, 2010, Pengertian dan

Dasar Hukum Perbankan, Sinar Grafika, Jakarta

Raharja Handikusuma, 2000, Hukum Koperasi Indonesia, PT. Raja Grafindo, Jakarta

Lukman Dendawijaya, 2005,

Manajemen Perbankan, Ghalia Indonesia, Jakarta

Julius R. Latumaerissa, 1999, Mengenal Aspek-Aspek Operasi Bank Umum, Bumi Aksara, Jakarta

Ismail, 2011, Manajmen Perbankan dari Teori Menuju Aplikasi, Kencana, Jakarta

Kasmir, 2012, Dasar-Dasar Perbankan Edisi Revisi, Rajawali Pers, Jakarta Supriono, 1998, Manajemen Strategi dan Kebijakan Bisnis, BPFE Yogyakarta, Yogyakarta

Thomas Suyatno, dkk, 1995, DasarDasar Perkreditan Edisi Keempat, Gramedia Pustaka Utama, Jakarta

Dermawan Wibisono, 2006, Manajemen Kinerja, Erlangga, Jakarta 
Ismail Solihin, 2009, Pengantar

Manajemen, Erlangga, Jakarta

Lawrence R. jauch dan William F.

Glueck, 1998, Manajemen Strategi

dan Kebijakan Perusahaan,

Erlangga, Jakarta

Lexy J. Moleong, 2005, Metodologi

Penelitian Kualitatif, PT. Remaja

Rosdakarya, Bandung

Saifudin Azwar, 1998, Metodologi

Penelitian, Pustaka Pelajar,

Yogyakarta

Muhammad, 2008, Metodologi

Penelitian Ekonomi Islam:

Pendekatan Kualitatif, PT. Raja

Grafindo Persada, Jakarta

Sutrisno Hadi, 1993, Metode Research

Jilid I, Andi Offset, Yogyakarta

Ali Zinuddin, 2010, Metode Penelitian

Hukum, Sinar Grafika, Jakarta

BadrulZaman, MariamDarus, 1994,

Aneke Hukum Bisnis, Alumni,

Bandung

Hermansyah, 2011, Hukum Perbankan

Nasional Indonesia, Edisi Revisi,

Jakarta 